doi: $10.15407 /$ ujpe62.03.0195

V.A. LITVINOV ${ }^{1}$ I.I. OKSENIUK, ${ }^{1}$ D.I. SHEVCHENKO, ${ }^{1}$ V.T. KOPPE,${ }^{1}$

V.V. BOBKOV, ${ }^{1}$ V.M. CHORNOUS ${ }^{2}$

${ }^{1}$ V.N. Karazin National University of Kharkiv

(31, Kurchatov Ave., Kharkiv 61108, Ukraine; e-mail: plip@meta.ua)

${ }^{2}$ Ivano-Frankivs'k National Technical University of Oil and Gas

(15, Karpats'ka Str., Ivano-Frankivs'k 76001, Ukraine)

PACS 34.35.+a, 79.20.Rf,

\title{
SIMS STUDY OF THE SURFACE
} OF TiFe HYDRIDE FORMING ALLOY

\begin{abstract}
The surfaces of specimens of TiFe hydrogen storage alloy have been studied with the use of secondary ion mass spectrometry. Even after the annealing of a specimen in vacuum and its cleaning with an ion beam, a substantial part of its surface is shown to remain coated with a bulky layer composed of oxides, hydrides, hydroxides, and carbides. This layer has to be taken into account when considering problems dealing with the kinetic parameters of hydride formation.

Keywords: hydrogen storage alloy, TiFe, hydride formation, surface, secondary ion mass spectrometry.
\end{abstract}

\section{Introduction}

The ability of some metals and alloys to reversibly absorb hydrogen in significant amounts stimulated the emergence of a number of technological solutions, in which this phenomenon is used in practice. This became possible because of a unique combination of properties inherent to the metal/hydrogen system: a capability to achieve extremely high bulk densities of hydrogen atoms $\left(0.09-0.1 \mathrm{~g} / \mathrm{cm}^{3}\right)$ in the metal lattice, wide operational intervals of temperatures and pressures, a selective character of the hydrogen absorption process, and some others. Owing to substantial efforts of researchers, a large number of hydrogen storage alloys (HSAs) have been synthesized for their application to various domains of technology and power engineering [1-3]. Besides the heat of hydride formation and the absorption ability, the main parameters of HSAs, which determine the efficiency of their practical application, include the rates of hydration and dehydration, the hysteresis degree, and the stability

(C) V.A. LITVINOV, I.I. OKSENIUK, D.I. SHEVCHENKO, V.T. KOPPE, V.V. BOBKOV, V.M. CHORNOUS, 2017

ISSN 2071-0194. Ukr. J. Phys. 2017. Vol. 62, No. 3 with respect to the action of impurities contained in hydrogen.

Numerous experimental researches of HSAs aimed at optimizing their properties, which were carried out earlier, were mainly devoted to the modification of their component composition. However, a number of issues - in particular, the role of the material surface - have been analyzed much less extensively. The surface plays a crucial role in the processes of interaction between the solid and gas phases and, thus, affects the entire complex of the problems associated with the parameters of a material used for the hydrogen storage. When studying the hydrogen sorptiondesorption processes, it is rather important to know the chemical composition of external monolayers on the surface.

The surface of an arbitrary metallic material is always covered with a smaller or larger amount of chemical compounds depending on experimental conditions [4]. To a great extent, those compounds govern the parameters of surface interaction with the gas phase. A clean surface can be obtained only as a result of special tricks, which are often difficult to be re- 
alized. The method of secondary ion mass spectrometry (SIMS) turned out useful, when being applied to study the composition of chemical compounds on the material surface. Together with its high sensitivity, SIMS possesses the unique ability to detect hydrogen. This method makes it possible to detect the presence of hydrogen and hydrogen-containing chemical compounds on the surface and in the near-surface layer, as well as to reveal composition modifications in those compounds depending on specific experimental conditions [5].

This work is devoted to the mentioned issue, namely, to the research of the chemical individuality that characterizes the surface of TiFe hydride-forming intermetallic alloy under various experimental conditions. The binary alloy TiFe, along with a number of intermetallic compounds, alloys, and composites, possesses an unique ability to reversibly absorb a significant amount of hydrogen from the gas phase. This alloy is of practical interest as a material for metal-hydride accumulators intended to be used for the hydrogen storage, transportation, and compression. The hydrogen capacitance of TiFe alloy reaches $1.86 \mathrm{wt} \%$ at the number of hydrogen atoms per formula unit $H / M=0.975$, and the reversible capacitance equals $1.5 \mathrm{wt} \%$. TiFe alloy has a body-centred cubic (BCC) structure. Its absorption isotherm has two well discernible plateaux, which points to the existence of two hydride phases [6-8]. Being characterized by moderate hydrogen sorption characteristics, TiFe alloy is rather attractive because of its low cost and the availability of corresponding raw materials. All that classifies it as a promising material for technologies used for the hydrogen production, storage, transportation, and compression.

TiFe-based alloys are hydrides with the dissociation pressure close to the atmospheric one at temperatures slightly above room temperature [6-8]. The major shortcomings of the HSAs of the TiFe type are the necessity of their activation, a high sensitivity to gas impurities in molecular hydrogen, and a considerable hysteresis at the absorption-desorption processes [9].

To simplify the activation of TiFe alloy, an excess of titanium is introduced into it. TiFe alloy is hydrated following the reactions of the types

$\mathrm{TiFe}+1 / 2 \mathrm{H}_{2} \rightarrow \mathrm{TiFeH}$,

$\mathrm{TiFeH}+1 / 2 \mathrm{H}_{2} \rightarrow \mathrm{TiFeH}_{2}$.
All alloys that are based on the TiFe system and used in practice are often doped with $\mathrm{Mn}, \mathrm{Cr}, \mathrm{Co}, \mathrm{Ni}$, and $\mathrm{V}$.

\section{Experimental Technique}

Monolithic specimens of $\mathrm{Ti}_{50} \mathrm{Fe}_{50}$ alloy were irradiated with a beam of $\mathrm{Ar}^{+}$ions with an energy of 8 or $16 \mathrm{keV}$, when analyzing positive or negative, respectively, secondary ions. The residual vacuum in the target chamber amounted to $4 \times 10^{-4} \mathrm{~Pa}$, when measuring the mass spectra, and $1 \times 10^{6} \mathrm{~Pa}$, when studying the dependences of the secondary ion intensity on the hydrogen partial pressure and the target temperature. The current density in the primary beam was varied from 1.5 to $10 \mu \mathrm{A} / \mathrm{cm}^{2}$, which corresponded to the dynamic SIMS mode [10].

The experimental installation was equipped with an energy filter, which allowed us to measure the emission intensity of only low-energy secondary ions, the latter providing the most complete information about the presence and composition of chemical compounds on the examined surface [11]. The emission intensities of secondary ions were measured in a dynamic range not narrower than six orders of magnitude. Before the measurements, the specimens were annealed in the residual vacuum at a temperature of about $1000 \mathrm{~K}$ in order to partially clean the surface from chemical compounds, which had been either desorbed or dissolved in the material bulk during the annealing. The annealing in the absence of a primary beam was accompanied by the emission of positive thermions of alkaline metals $\mathrm{Na}^{+}, \mathrm{K}^{+}, \mathrm{Rb}^{+}$, and $\mathrm{Cs}^{+}$. At temperatures above $650 \mathrm{~K}$, the emission of thermions $\mathrm{Ti}^{+}$and $\mathrm{Fe}^{+}$, as well as $\mathrm{TiO}^{+}, \mathrm{TiO}_{2}{ }^{+}$, $\mathrm{TiO}_{3}{ }^{+}$, and $\mathrm{Ti}_{2} \mathrm{O}^{+}$, was also observed. This fact is a direct confirmation of the surface cleaning through the decomposition and desorption of chemical compounds (oxides and hydroxides).

After the annealing, the surface was cleaned, by using a beam of primary ions till the full stabilization of the mass-spectrum composition and the emission intensities of secondary ions. The gas phase composition was monitored and the partial pressure of hydrogen was measured with the help of a gas mass spectrometer MX 7304 after its required calibration.

\section{Experimental Results and Their Discussion}

The analysis of the results obtained testifies that the mass spectra of positive and negative secondary ions

ISSN 2071-0194. Ukr. J. Phys. 2017. Vol. 62, No. 3 


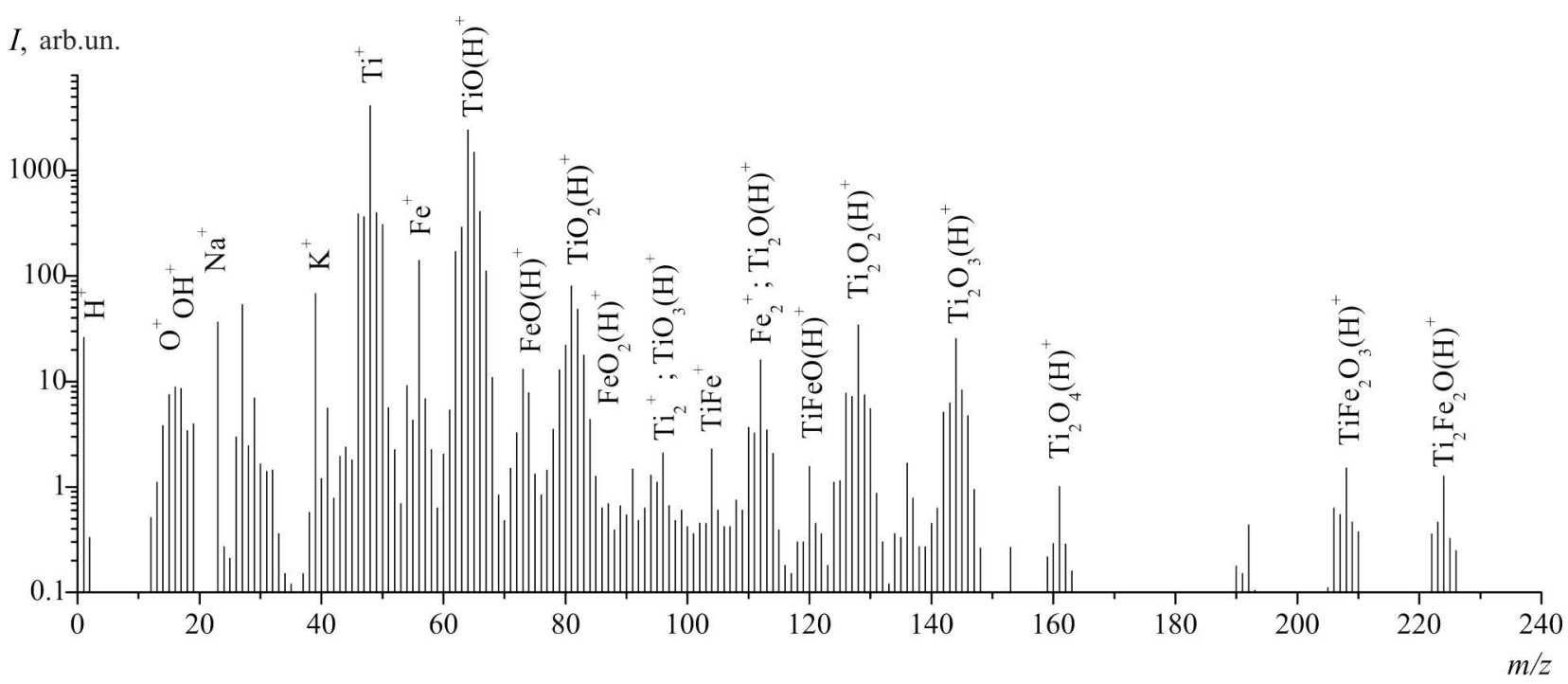

Fig. 1. Panoramic mass spectrum of positive secondary ions sputtered from the surface of a specimen of TiFe alloy at room temperature in the residual vacuum and at a primary beam current density of $1.5 \mu \mathrm{A} / \mathrm{cm}^{2}$

$I$, arb. un.

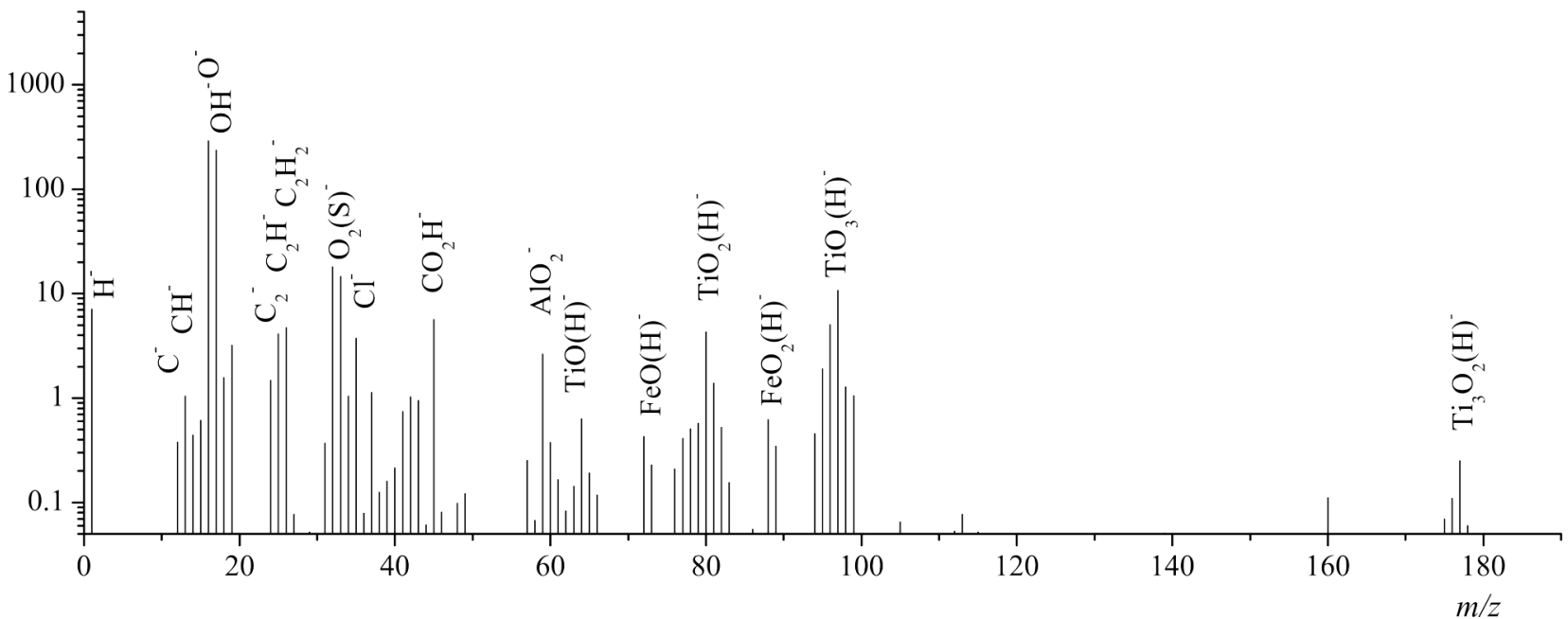

Fig. 2. Panoramic mass spectrum of negative secondary ions sputtered from the surface of a specimen of TiFe alloy at room temperature in the residual vacuum, and at a primary beam current density of $1.5 \mu \mathrm{A} / \mathrm{cm}^{2}$

contain a considerable number of emissions associated with the matrix material. These are atomic and cluster Ti and Fe ions and intermetallic ions of titanium and iron. There are also a considerable number of emissions corresponding to the compounds of matrix atoms with hydrogen, oxygen, and carbon. Figures 1 and 2 demonstrate examples of mass spectra obtained for the positive and negative ions sputtered from the alloy surface.
Before proceeding to the discussion of compositions of the mass spectrum, the following circumstances have to be marked. Since the sputtered ions are fragments of the surface and near-surface monolayers of the solid, they characterize the composition and the number of chemical compounds on the surface and in the near-surface layer. However, the emission of oneand even two-atomic secondary ions is not very informative as a rule, because those ions can be fragments 
of absolutely different chemical compounds located on the surface. At the same time, the emission of complex ions composed of several atoms characterizes, to a large extent, the "parent" structure, i.e. the atomic complex that the ionized fragments are knocked out from $[12,13]$.

Information about the composition and the state of the surface, which is obtained by analyzing those emissions, is more reliable. From this viewpoint, the emissions of $\mathrm{FeO}_{3}(\mathrm{H})^{+}, \mathrm{Fe}_{2} \mathrm{O}(\mathrm{H})^{+}$,

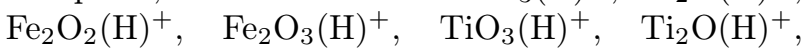
$\mathrm{Ti}_{2} \mathrm{O}_{2}(\mathrm{H})^{+}, \quad \mathrm{Ti}_{2} \mathrm{O}_{3}(\mathrm{H})^{+}, \quad \mathrm{Ti}_{2} \mathrm{O}_{4}(\mathrm{H})^{+}, \quad \mathrm{Ti}_{3} \mathrm{O}(\mathrm{H})^{+}$, $\mathrm{Ti}_{3} \mathrm{O}_{2}(\mathrm{H})^{+}, \mathrm{Ti}_{3} \mathrm{O}_{3}(\mathrm{H})^{+}, \mathrm{TiFeO}_{3}(\mathrm{H})^{+}, \mathrm{TiFe}_{2} \mathrm{O}_{2}(\mathrm{H})^{+}$, $\mathrm{TiFe}_{2} \mathrm{O}_{3}(\mathrm{H})^{+}$, and other ions, which are observed in the presented mass spectrum, are the most interesting. The presence of such emissions in the spectrum gives us ground to consider that, under the indicated experimental conditions, the surface of researched alloy specimens is covered with chemical compounds, which includes oxides, hydrides, hydroxides, and carbides. Furthermore, the both alloy components, titanium and iron, form chemical compounds with oxygen, hydrogen, and carbon. Some of those compounds have a three-dimensional structure, because it is rather improbable that a secondary ion containing more than five atoms, e.g. $\mathrm{TiFe}_{2} \mathrm{O}_{3}(\mathrm{H})^{+}$, would be a fragment of the two-dimensional structure inherent to the monolayer coating.

The presence of such chemical compounds is mainly associated with the interaction between the surface and the gas phase components. This assertion is confirmed by the fact that, when the vacuum conditions were improved to a residual pressure of $1 \times 10^{-6} \mathrm{~Pa}$, a substantial decrease in the emission intensity of ions containing oxygen and the $\mathrm{OH}$ group was registered. Simultaneously, the increase in the emission intensities of cluster ions $\mathrm{TiFe}^{+}, \mathrm{TiFe}_{2}{ }^{+}, \mathrm{Ti}_{2} \mathrm{Fe}^{+}$, and $\mathrm{Ti}_{2} \mathrm{Fe}_{2}{ }^{+}$was observed. This fact testifies to the cleaning of the alloy surface from oxides and hydroxides. A certain contribution to the composition of surface compounds is also made by impurities in the bulk. As a whole, this situation is typical of complex metallic objects under similar experimental conditions $[5,14,15]$.

In this work, TiFe alloy was considered from the viewpoint of its hydrogen-sorption properties. Therefore, the dependences of the secondary ion current on the partial pressure of hydrogen in the target chamber were measured first of all. In Fig. 3, some of them, which were registered for a number of emissions, are depicted.

We should note that, in the case of TiFe specimen, a considerable number of emissions for multiatomic secondary ions, which are the most informative with respect to the composition of chemical compounds on the surface, overlap one another in the mass coordinate. Their resolution following the standard procedure, which takes the natural abundance of isotopes into account, can insert an unacceptably high error. For this reason, in Fig. 3, the dependences are presented for those secondary ions, whose identification is not difficult. Since such ions are fragments of the "parent" surface structure, their dependences on the partial pressure of hydrogen give us a general idea concerning the transformation of chemical compounds on the surface.

The analysis of experimental dependences testifies that the increase of the partial pressure of hydrogen in a target chamber from $8 \times 10^{-7}$ to $9 \times 10^{-3} \mathrm{~Pa}$ gives rise to the emission intensity growth. Furthermore, for the majority of secondary ions, their dependences have tendency to be saturated at high pressures. Only the emissions for oxide and carbide ions remain almost invariable. The emissions for hydride ions demonstrate the largest growth. In particular, the emission intensities for hydride ions of separate alloy components and for complex ions of the type $\mathrm{Ti}_{n} \mathrm{Fe}_{m} \mathrm{H}_{k}^{+}$, as well as more complicated ones, increase by one to two orders of magnitude. The ion emission for hydroxides has a smaller growth. Those facts give us ground to assume that a bulk layer of chemical compounds consisting of the hydrides and hydroxides of the alloy components is formed on the specimen surface within the indicated interval of the partial hydrogen pressure and at room temperature. The absence of features like jumps or cusps in the presented dependences testifies to a regular character of the formation of hydrogen-enriched compounds on the surface with the hydrogen flux growth.

In order to determine how the specimen temperature affects the processes of interaction of a specimen with hydrogen and to trace changes in the surface composition at the heating, the temperature dependences of the emission intensities were measured for various secondary ions in a temperature interval from room temperature to $900 \mathrm{~K}$. In the case of hydride ions, the measurements were carried out at the partial hydrogen pressure $P_{\mathrm{H}_{2}}=3.5 \times 10^{-4} \mathrm{~Pa}$. The

ISSN 2071-0194. Ukr. J. Phys. 2017. Vol. 62, No. 3 

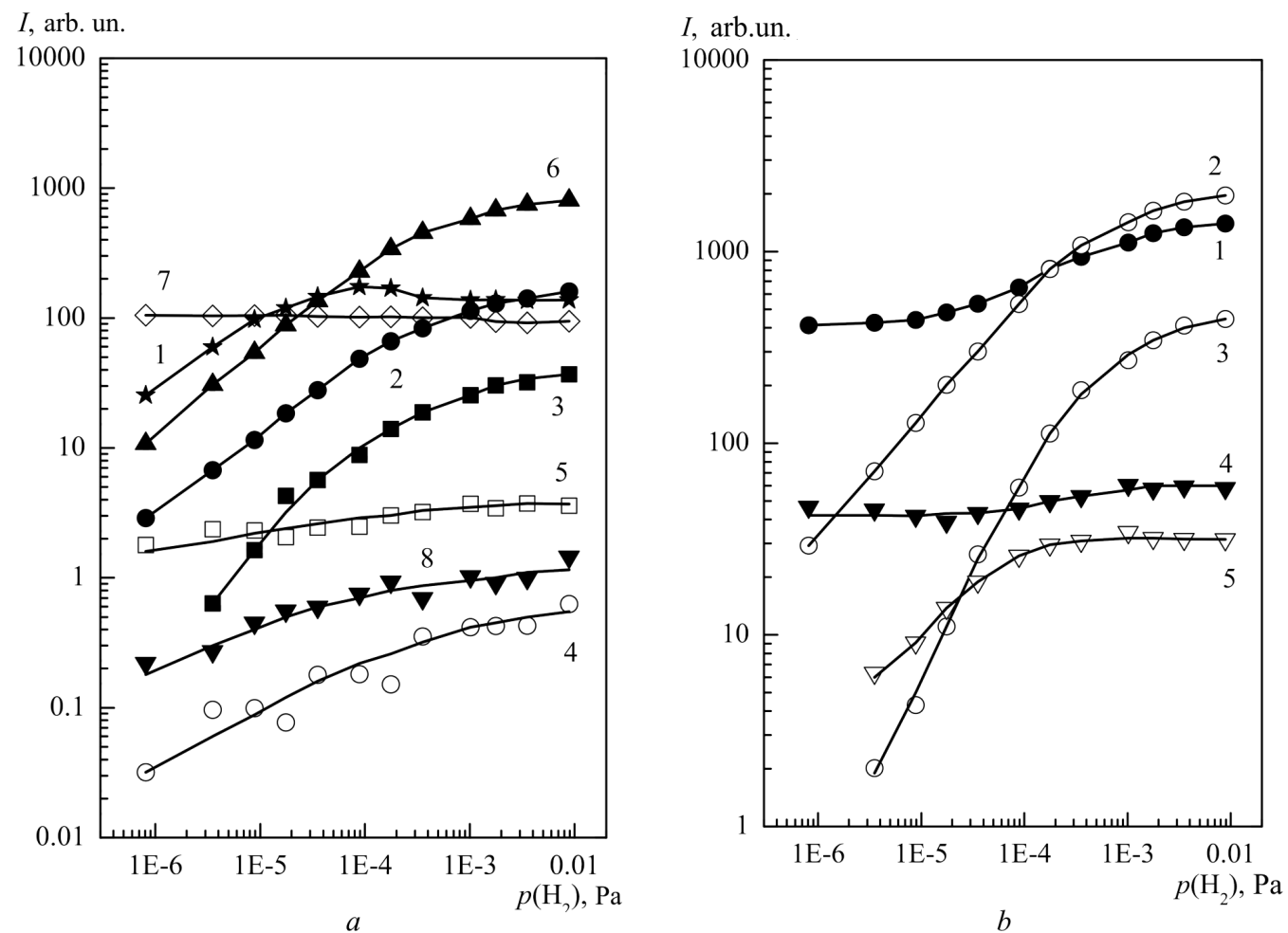

Fig. 3. Dependences of the emission intensity on the hydrogen partial pressure in a target chamber for positive secondary ions sputtered from the TiFe alloy surface at the temperature $T=293 \mathrm{~K}$ and a primary beam current density of $6.0 \mu \mathrm{A} / \mathrm{cm}^{2}$; panel $a: \mathrm{H}^{+}(1),{ }^{50} \mathrm{TiH}^{+}(2),{ }^{56} \mathrm{FeH}^{+}(3),{ }^{50} \mathrm{TiOH}^{+}(4)$, ${ }^{56} \mathrm{FeOH}^{+}(5), \mathrm{TiFeH}^{+}(m=105 \mathrm{amu})(6),{ }^{48} \mathrm{TiO}^{+}(7)$, and $\mathrm{CH}^{+}(8)$; panel $b:{ }^{48} \mathrm{Ti}_{2}{ }^{+}(1),{ }^{48} \mathrm{Ti}_{2} \mathrm{H}^{+}$ (2), ${ }^{48} \mathrm{Ti}_{2} \mathrm{H}_{2}+$ (3), ${ }^{48} \mathrm{Ti}_{2} \mathrm{C}^{+}$(4), and ${ }^{48} \mathrm{Ti}_{2} \mathrm{CH}^{+}$(5)

corresponding temperature dependences obtained for some emissions are depicted in Fig. 4. Their analysis shows that, when the temperature grows from room temperature to about $900 \mathrm{~K}$, the emission intensities for the hydride ions of alloy components decrease by two to three orders of magnitude. The emission intensities for carbide ions remain almost constant. For the oxide ions $\mathrm{TiO}^{+}$and $\mathrm{TiFeO}^{+}$, some intensity growth is observed at temperatures above $600 \mathrm{~K}$.

Hence, the temperature growth gives rise to a reduction in the amount of hydrogenous chemical compounds (hydrides of alloy components) on the surface and a qualitative modification of their composition. This is a result of a decrease of the hydrogen sorption from the gas phase (owing to the diminishing of the sticking coefficient as the temperature grows), a reduction of the temperature stability of hydrides, and an intensification of the desorption from the surface. The measured temperature dependences for the ions of alloy component oxides provide an additional confirmation that a considerable fraction of the alloy surface is covered with a bulky oxide layer.

According to the modern viewpoint $[7,16]$, the formation of metal hydrides in the hydrogen atmosphere includes a few stages. The surface stages include the physical adsorption and dissociation (atomization) of adsorbed $\mathrm{H}_{2}$ molecules. The diffusive stages include the bulk diffusion and diffusion of hydrogen atoms along the grain boundaries in the material giving rise to the formation, first, of an interstitial solid solution ( $\alpha$-phase) and, afterward, metal hydride $(\beta$ phase). The formation of hydride phases consists in the nucleation of grains, their growth, and solid-phase transformations. The metal hydride is characterized by a substantially higher content of hydrogen atoms and their ordered arrangement in the crystal lattice.

Our researches demonstrate that this description is a little simplified. The analysis of the registered mass spectra of secondary ions, as well as their dependences on the temperature and the hydrogen par- 

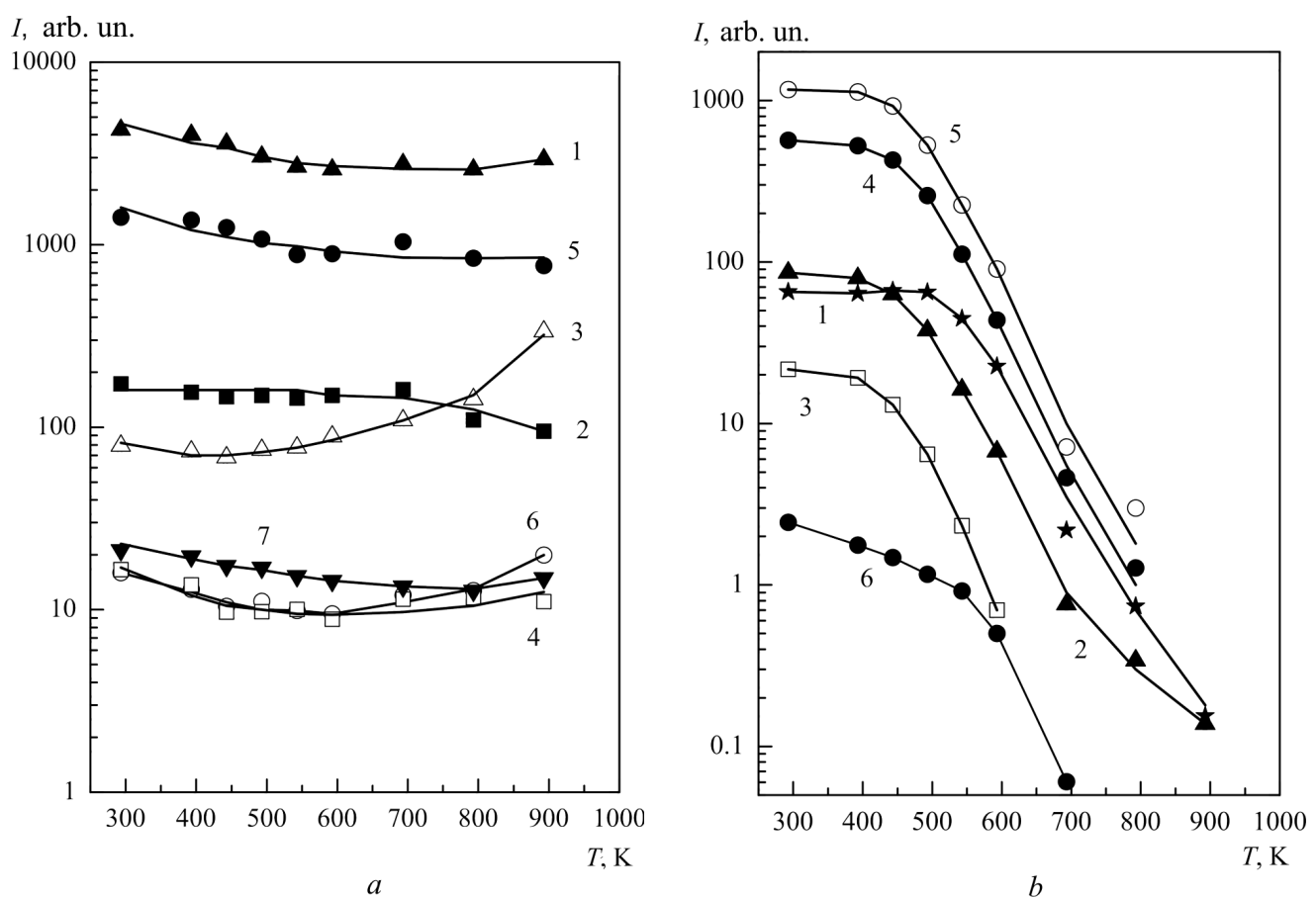

Fig. 4. Temperature dependences of the emission intensity for positive secondary ions sputtered from the surface of the TiFe alloy specimen at the hydrogen partial pressure $P_{\mathrm{H}_{2}}=3.5 \times 10^{-4} \mathrm{~Pa}$ and a primary beam current density of $6.0 \mu \mathrm{A} / \mathrm{cm}^{2}$; panel $a:{ }^{48} \mathrm{Ti}^{+}$(1), ${ }^{56} \mathrm{Fe}^{+}$(2), ${ }^{48} \mathrm{TiO}^{+}(3),{ }^{56} \mathrm{FeO}^{+}(4)$, $\mathrm{TiFe}^{+}(m=104 \mathrm{amu})(5), \mathrm{TiFeO}^{+}(m=120 \mathrm{amu})(6)$, and ${ }^{48} \mathrm{TiC}^{+}$(7); panel $b: \mathrm{H}^{+}(1),{ }^{48} \mathrm{TiH}^{+}$ (2), ${ }^{56} \mathrm{FeH}^{+}$(3), $\mathrm{TiFeH}^{+}(m=105 \mathrm{amu})(4),{ }^{48} \mathrm{Ti}_{2} \mathrm{H}^{+}$(5), and $\mathrm{CH}^{+}$(6)

tial pressure, makes it possible to assert that, even after the annealing of the specimen in vacuum and a long-term cleaning of its surface with the use of a primary beam, a substantial fraction of the specimen surface remains covered with a bulky layer of chemical compounds including hydrides, oxides, carbides, and hydroxides. Therefore, we have every reason to believe that hydrogen molecules are not adsorbed on a clean surface of the material with their subsequent diffusion into the specimen bulk; instead, this is a surface covered with a bulky layer of chemical compounds. The penetration of hydrogen through this layer is governed by a number of elementary physicochemical processes. Diffusion is the main component of those processes.

Since hydrogen diffuses into the material as hydrogen atoms, the energy parameters of the surface associated with its chemical composition and the dynamics of this composition variations depending on external conditions are important. It is evident that the rate of hydrogen molecule dissociation into atoms and their further diffusion are substantially different from those for the clean surface and the surface covered with chemical compounds. One should pay attention that the preparation of a clean surface in the case of real materials and under real experimental conditions is a very hard task. On this basis, when discussing the issues concerning the formation of metal hydrides, it is necessary to consider the processes of hydrogen sorption not only on a clean alloy surface, but also on a surface covered with oxides, hydrides, hydroxides, and carbides, as well as the processes of diffusion through those coatings.

In order to determine the role of each alloy component in the hydride formation process, similar temperature dependences and dependences on the hydrogen partial pressure were measured for pure titanium and pure iron specimens. The measurements showed that the dependences obtained for some typical secondary ions sputtered from the surface of each pure metal had no principal differences from the corresponding dependences obtained for ions sputtered from the alloy surface. This fact allowed us to draw a conclusion that the association of titanium and iron 
atoms into a common crystal lattice substantially modifies the bulk lattice properties with respect to its hydrogen accumulation ability, but does not introduce additional factors that could affect the composition of chemical compounds on the surface.

\section{Conclusions}

Our researches have shown that, under environmental conditions, a significant fraction of the surface of TiFe hydride-forming alloy, which is used as a hydrogen storage material, is covered with a bulky layer of chemical compounds: oxides, hydrides, hydroxides, and carbides. This fact has to be taken into consideration, when analyzing the processes of metal hydride formation, because the surface state of the alloy substantially affects the dissociation of hydrogen molecules at the adsorption, and the process of dissociative chemisorption plays a crucial role for the diffusion and accumulation of hydrogen in the alloy bulk. Therefore, the dependence of the hydrogensorption properties of the alloy, in particular, the kinetic parameters of hydride formation on its surface, on the processes of dissociative chemisorption of hydrogen implies a possibility to modify those properties by purposefully changing the state or the composition of chemical compounds on the alloy surface.

1. P. Dantzer. Metal-hydride technology: A critical review. In Hydrogen in Metals. III. Properties and Applications (Springer, 1997), p. 279 [DOI: 10.1007/BFb0103405].

2. V.M. Azhazha, M.A. Tikhonovsky, A.G. Shepelev, Yu.P. Kurilo, T.A. Ponomarenko, D.V. Vinogradov. Hydrogen storage materials: Analysis of trends in the progress based on the data retrieved from information flows. Vopr. At. Nauki Tekhn. No. 1, 145 (2006) (in Russian).

3. A.N. Perevesenzev, B.M. Andreev, V.K. Kapyshev, L.A. Rivkis, M.P. Malek, V.M. Bystritskii, V.A. Stolupin. Hydrides of intermetallic compounds and alloys, their properties and application in atomic technology. Fiz. Elem. Chast. At. Yadra 19, 1386 (1988) (in Russian).

4. V.T. Cherepin. Ion Probe (Naukova Dumka, 1981) (in Russian).

5. V.A. Litvinov, V.T. Koppe, V.V. Bobkov. SIMS investigations of hydrogen interaction with a zirconium getter alloy surface. Bull. Russ. Acad. Sci. Phys. 76, 553 (2012) [DOI: 10.3103/S1062873812050152].

6. J.J Reilly, R.H. Wiswall. Formation and properties of iron titanium hydride. Inorg. Chem. 13, 218 (1974) [DOI: 10.1021/ic50131a042].
7. G. Sandrock. A panoramic overview of hydrogen storage alloys from a gas reaction point of view. J. Alloys Compd. 293-295, 877 (1999) [DOI: 10.1016/S09258388(99)00384-9].

8. B.A. Kolachev, R.E. Shalin, A.A. Ilyin. Hydrogen Storage Alloys (Metallurgiya, 1995) (in Russian).

9. D.G. Ivey, D.O. Northwood. Storing energy in metal hydrides: a review of the physical metallurgy. J. Mater. Sci. 18, 321 (1983) [DOI: 10.1007/BF00560621].

10. A. Benninghoven, F.G. Rüdenauer, H.W. Werner. Secondary Ion Mass Spectrometry: Basic Concepts, Instrumental Aspects, Applications, and Trends (Wiley, 1987) [ISBN: 978-0471010562].

11. V.A. Litvinov, A.G. Koval, B.M. Fizgeer. On the energy spectra of secondary ions sputtered from the surface of certain metals and their oxides. Izv. Akad. Nauk SSSR Ser. Fiz. 55, 2423 (1991) (in Russian).

12. Ya.M. Fogel'. Ion-ion emission - A new tool for massspectrometric investigations of processes on the surface and in the bulk of solids. Int. J. Mass Spectrom. Ion Phys. 9, 109 (1972) [DOI: 10.1016/0020-7381(72)80037-8].

13. Ya.M. Fogel'. To the selection of the current density magnitude in the primary-ion beam when studying the proceses on a solid surface using the secondary ion-ion emissin method. Zh. Tekhn. Fiz. 46, 1787 (1976) (in Russian).

14. J.C. Vickerman, A. Brown, N.M. Reed. Secondary Ion Mass Spectrometry: Principles and Applications (Clarendon Press, 1989) [ISBN: 0-19-855625-X].

15. K. Hamer, W. Gerhard, C. Plog, R. Kaufmann. LAMMAand SIMS/AES-measurements on Fe-Ti-alloys. Fresenius Z. Anal. Chem. 308, 287 (1981) [DOI: 10.1007/ BF00479642].

16. Z.A. Matysina, D.V. Shchur. Hydrogen and Solid-Phase Transformations in Metals, Alloys, and Fullerites (Nauka i Obrazovanie, 2002) (in Russian).

Received 16.06.16.

Translated from Ukrainian by O.I. Voitenko

В.О. Літвінов, І.І. Оксенюк, Д.І. Шевченко,

B.T. Konnе, B.В. Бобков, В.М. Чорноус

ВІМС ДОСЛІДЖЕННЯ ПОВЕРХНІ

ГІДРИДОУТВОРЮЮЧОГО СПЛАВУ ТіFе

Р е з ю м е

Методом вторинної іонної мас-спектрометрії проведено дослідження поверхні зразків сплаву-накопичувача водню TiFe. Показано, що навіть після відпалу в вакуумі і очищення іонним пучком значна частина поверхні зразків покрита об'ємним шаром оксидів, гідридів, гідрооксидів і карбідів. Наявність такого шару необхідно враховувати при розгляді питань, пов'язаних з кінетичними параметрами процесів гідридоутворення. 